\title{
Mid- and long-term outcomes of thoracic endovascular aortic repair in acute and subacute uncomplicated type B aortic dissection
}

\author{
Matti Jubouri ${ }^{1}$, Mohammed Al-Tawil ${ }^{2}$, Ho Cheung Anthony Yip ${ }^{3}$, Ali Bashir ${ }^{4}$, Sven Zhen \\ Cian Patrick Tan $^{5}$, Mohamad Bashir ${ }^{6}$, Richard Anderson ${ }^{7}$, Damian Bailey ${ }^{8}$, Christoph \\ Nienaber $^{9}$, Joseph Coselli ${ }^{10}$, and Ian Williams ${ }^{7}$ \\ ${ }^{1}$ Hull York Medical School \\ ${ }^{2} \mathrm{Al}$ Quds University Faculty of Medicine \\ ${ }^{3}$ St George's University of London \\ ${ }^{4}$ Carol Davila University of Medicine and Pharmacy Faculty of General Medicine \\ ${ }^{5}$ Queen Mary University of London Barts and The London School of Medicine and \\ Dentistry \\ ${ }^{6}$ NHS Wales Health Education and Improvement Wales \\ ${ }^{7}$ University Hospital of Wales \\ ${ }^{8}$ University of South Wales Faculty of Life Sciences and Education \\ ${ }^{9}$ Royal Brompton and Harefield Hospitals \\ ${ }^{10}$ Baylor College of Medicine Michael E DeBakey Department of Surgery
}

January 24, 2022

\begin{abstract}
Background: Uncomplicated type B aortic dissection (un-TBAD) has been managed conservatively with medical therapy in order to control the heart rate and blood pressure to limit disease progression, in addition to radiological follow-up. However, several trials and observational studies have investigated the use of thoracic endovascular aortic repair (TEVAR) in un-TBAD and suggested that TEVAR provides a survival benefit over medical therapy. Outcomes of TEVAR have also been linked with the timing of intervention. Aims: The scope of this review is to collate and summarise all the evidence in the literature on the mid- and long-term outcomes of TEVAR in un-TBAD, confirming its superiority. We also aimed to investigate the relationship between timing of TEVAR intervention and results. Methods: We carried out a comprehensive literature search on multiple electronic databases including PubMed, Scopus and EMBASE in order to collate and summarise all research evidence on the mid- and long-term outcomes of TEVAR in un-TBAD, as well as its relationship with intervention timing. Results: TEVAR has proven to be a safe and effective tool in un-TBAD, offering superior mid- and long-term outcomes including all-cause and aorta-related mortality, aortic-specific adverse events, aortic remodelling, and need for reintervention. Additionally, performing TEVAR during the subacute phase of dissection seems to yield optimal results. Conclusion: The evidence demonstrating a survival advantage in favour TEVAR over medical therapy in un-TBAD means that with further research, particular trials and observational studies, TEVAR could become the gold-standard treatment option for un-TBAD patients.
\end{abstract}

Mid- and long-term outcomes of thoracic endovascular aortic repair in acute and subacute uncomplicated type $\mathrm{B}$ aortic dissection

Matti Jubouri ${ }^{1 *}$, Mohammed Al-Tawil ${ }^{2 *}$, Ho Cheung Anthony Yip ${ }^{3}$, Ali Bashir ${ }^{4}$, Sven ZCP Tan ${ }^{5}$, Mohamad Bashir MD PhD MRCS ${ }^{6}$, Richard Anderson BSc MBBS MD ${ }^{7}$, Damian Bailey PhD FRSC FPVRI FACSM FTPS $^{8}$, Christoph A. Nienaber MD PhD MRCP ${ }^{9}$, Joseph S. Coselli MD ${ }^{10,11,12}$, Ian Williams MD FRCS ${ }^{13}$ 
1. Hull York Medical School, University of York, York, UK*

2. Faculty of Medicine, Al-Quds University, Jerusalem, Palestine*

3. St. George's, University of London, London, UK

4. Carol Davila University of Medicine and Pharmacy, Bucharest, Romania

5. Barts and The London School of Medicine and Dentistry, Queen Mary University of London, UK

6. Vascular \& Endovascular Surgery, Velindre University NHS Trust, Health Education \& Improvement Wales (HEIW), Cardiff, Wales, UK

7. Department of Cardiology, University Hospital of Wales, Heath Park, Cardiff, UK

8. Neurovascular Research Laboratory, Faculty of Life Sciences and Education, University of South Wales, Pontypridd, UK

9. Cardiology and Aortic Centre, Royal Brompton and Harefield Hospital NHS Foundation Trust, London, UK.

10. Division of Cardiothoracic Surgery, Michael E. DeBakey Department of Surgery, Baylor College of Medicine, Houston, Texas, USA

11. Department of Cardiovascular Surgery, Texas Heart Institute, Houston, Texas, USA

12. CHI St Luke's-Baylor St. Luke's Medical Center, Houston, Texas, USA

13. Department of Vascular Surgery, University Hospital of Wales, Heath Park, Cardiff, UK

* These authors contributed equally to this manuscript, therefore they are joint-first authors.

\section{Correspondence:}

Mohamad Bashir MD PhD MRCS

Vascular \& Endovascular Surgery

Velindre University NHS Trust

Health Education \& Improvement Wales (HEIW)

Cardiff CF15 7QZ

UK

Email: drmobashir@outlook.com

Keywords: Type B Aortic Dissection, Aortic Dissection, TEVAR, Aortic Surgery

COI: None

Funding: Damian Bailey is funded by a Royal Society Wolfson Research Fellowship (\#WM170007) and separate grants from the Royal Society (IES/R2/192137) and Japan Society for the Promotion of Science (JSPS/OF317). Otherwise no funding received.

Ethical approval: No ethical approval required for this review.

Guarantor: Mohamad Bashir (MB)

Contributorship: MJ, MT, HCAY and $\mathrm{AB}$ involved in literature review design, literature search, and manuscript writing. SZCPT, MB, RA, DMB, CN, JC and IW involved in manuscript revision.

Acknowledgements: None

\section{Abstract}

Background: Uncomplicated type B aortic dissection (un-TBAD) has been managed conservatively with medical therapy in order to control the heart rate and blood pressure to limit disease progression, in addition to radiological follow-up. However, several trials and observational studies have investigated the use of thoracic endovascular aortic repair (TEVAR) in un-TBAD and suggested that TEVAR provides a survival benefit over medical therapy. Outcomes of TEVAR have also been linked with the timing of intervention. 
Aims: The scope of this review is to collate and summarise all the evidence in the literature on the midand long-term outcomes of TEVAR in un-TBAD, confirming its superiority. We also aimed to investigate the relationship between timing of TEVAR intervention and results.

Methods: We carried out a comprehensive literature search on multiple electronic databases including PubMed, Scopus and EMBASE in order to collate and summarise all research evidence on the mid- and long-term outcomes of TEVAR in un-TBAD, as well as its relationship with intervention timing.

Results: TEVAR has proven to be a safe and effective tool in un-TBAD, offering superior mid- and long-term outcomes including all-cause and aorta-related mortality, aortic-specific adverse events, aortic remodelling, and need for reintervention. Additionally, performing TEVAR during the subacute phase of dissection seems to yield optimal results.

Conclusion: The evidence demonstrating a survival advantage in favour TEVAR over medical therapy in unTBAD means that with further research, particular trials and observational studies, TEVAR could become the gold-standard treatment option for un-TBAD patients.

\section{Introduction}

Stanford type B aortic dissections (TBAD) involve an entry tear in the intimal layer of the aorta distal to the left subclavian artery (LSA). Blood leaves the true lumen (TL) into the false lumen (FL), which expands over time and can eventually rupture [1]. This original entry tear can propagate antegrade or retrograde and may result in static obstruction of a branch vessel and malperfusion/ischaemia of end-organs. The other mechanism for malperfusion is via dynamic obstruction, which is more common and caused by intermittent blockage of a branch vessel by the mobile intimomedial dissection flap [2].

TBAD can be subcategorised based on presence of complications and time frame. Complicated TBAD (coTBAD) exhibits certain symptoms on presentation which associate it with higher mortality and morbidity. The two principal complications are aortic rupture and end-organ malperfusion. If rupture or malperfusion are absent then the TBAD is classified as uncomplicated TBAD (un-TBAD). Using time of onset, TBAD can be classified as acute ( $<15$ days since symptom onset), subacute (15-90 days since symptom onset), and chronic (>90 days since symptom onset) [1]. However, the onset-based classification of TBAD according to the International Registry of Acute Aortic Dissection (IRAD) is hyperacute $(<24 \mathrm{~h})$, acute $(2-7$ days), subacute ( $8-30$ days), and chronic ( $>30$ days). Knowing the time phase of TBAD is clinically important as the dissection flap becoming less compliant over time which may negatively influence aortic remodelling [3].

Un-TBAD is managed conventionally with optimal medical therapy (OMT), also known as best medical therapy $(\mathrm{BMT})$, to strictly regulate the heart rate $(<60 \mathrm{bpm})$ and blood pressure (systolic $\mathrm{BP}<100-120$ $\mathrm{mmHg})[4,5]$. However, un-TBAD patients who are discharged with OMT alone maybe lost to follow-up and the disease progresses to become fatal. Some survival analyses showed that up to $50 \%$ of un-TBAD patients on OMT alone were dead by 5-years [5]. Several trials and observational studies have investigated the use of thoracic endovascular aortic repair (TEVAR) for un-TBAD in an effort to shift the paradigm), but there are certain high risk features which may need be considered if a stent graft is an option [4]. These were summed up nicely in a recent interesting review by Jubouri et al. [4] who combined the evidence from these studies, including the INSTEAD, INSTEAD-XL, and ADSORB trials, as well as multiple retrospective studies. All of these which proved the TEVAR does offer a long-term survival advantage and improved aortic remodelling in un-TBAD patients relative to OMT alone. Jubouri et al. [4] also looked at how the timing of TEVAR intervention influences outcomes and confirmed TEVAR in the subacute phase of un-TBAD yielded optimum results. To assess any superiority, the aim of this review is to sum up the evidence in the literature on the mid- and long-term outcomes on TEVAR in un-TBAD.

\section{Late outcomes ( $>30$ days)}

\subsection{All-cause mortality}

Multiple observational studies have been published in recent years to ascertain the impact of TEVAR in acute 
or subacute un-TBAD. Most studies mentioned have an identical time-based classification of un-TBAD $(<14$ days for acute, 15-90 days for subacute, and $>90$ days for chronic since symptom onset) unless otherwise stated. Among these studies, some have investigated the mid- and long-term all-cause mortality rates in patients with different subtypes of TBAD receiving TEVAR. One such example is a retrospective study conducted by Tjaden et al. [6]. Two hundred and sixty four patients who had undergone TEVAR for TBAD (170 acute and 94 chronic) were selected from the Global Registry of Endovascular Aortic Treatment for analysis. Throughout a mean follow-up period of 26 months, the study reported that the total all-cause mortality is significantly higher in patients with chronic TBAD than in those with acute TBAD (19.2\% versus $8.8 \% ; \mathrm{P}=0.02$ ). However, on further analysis, it was found that the specific overall survival (calculated as 1 minus all-cause mortality) for acute un-TBAD ( $n=69,26 \%$ of study group) was significantly higher $(\mathrm{P}<0.05)$ than any other subtypes of TBAD $(93 \%$ vs $83 \%$ at 2 years, respectively).

In another retrospective study by Torrent et al. [7] which involved the evaluation of the data from the Vascular Quality Initiative TEVAR and complex endovascular aneurysm repair. Over 600 un-TBAD patients were included (446 acute and 242 subacute). The analysis of the information from the registry established that the 1-year mortality rates for acute and subacute un-TBAD patients treated by TEVAR were $13.3 \%$ and $8.2 \%$ respectively. Furthermore, the difference in mortality rates for the 2 groups was not significant $(\mathrm{P}=0.129)$. This finding is supported by Xie. et al. [8] who reported no difference in all-cause mortality between acute and sub-acute $(4.2 \%$ and $8.3 \%$ respectively) un-TBAD patients treated with TEVAR. The study (follow-up duration up to 106 months) consisted of 267 patients divided into 2 groups (130 acute and 137 subacute) depending on when TEVAR was performed. Additionally, Xiang et al. [9] also reported findings for 238 acute un-TBAD patients, again divided into 2 groups depending on the timing of TEVAR (142 acute and 96 subacute). By 5 years, there was no difference seen between acute and subacute patients in terms of all-cause mortality ( $7.3 \%$ and $12.4 \%$ respectively). These results suggest that there are relatively low mid- to long-term (1-5 years) all-cause mortality rates for acute and subacute un-TBAD patients postTEVAR. Furthermore, the difference between the 2 groups was also insignificant $(\mathrm{P}=0.39)$.

Other retrospective studies have also reported on the survival rates for un-TBAD patients post-TEVAR. Spinelli et al. [10] retrospectively analysed patient data from the Global Registry for Endovascular Aortic Treatment. In this registry, 172 patients with acute TBAD underwent TEVAR (102 complicated TBAD and 70 un-TBAD). The overall survival rates for acute un-TBAD at 1 year and 3 years were reported $(96.8 \% \pm 3.1 \%$ and $90.4 \% \pm 9.5 \%$, respectively). Bi et al. [11] also published overall survival rates at 3-year post-TEVAR and found $95.5 \%$ for acute ( $<15$ days) and $100 \%$ for subacute $(15-92$ days $)$ TBAD. The study included a total of 53 acute and subacute TBAD patients randomized into 3 groups (22 acute TBAD + TEVAR; 18 subacute TBAD + TEVAR; 13 TBAD + non-operative treatment). Also, number of mortalities due to complications (i.e. aortic rupture, low cardiac output, bleeding, multiple organ failure) across the follow-up period for both groups of patients that received TEVAR were reported to be zero, whilst the non-operative group only showed 4 deaths. The results of this study, however, is not completely compatible with this review as only 47 acute/subacute un-TBAD patients were included in this study.

Further studies have sought to compare the difference in mortality outcomes in set patient groups that received different forms of treatments for acute un-TBAD. In a study by Qin and colleagues [12], patients with acute un-TBAD across 3 medical centres were retrospectively identified. Three hundred and thirty eight fulfilled the study's inclusion criteria, of which, 184 received TEVAR while the remaining 154 received BMT. The all-cause mortality was significantly higher $(\mathrm{P}=0.01)$ in those receiving BMT across a follow-up period of up to 11 years. Correspondingly, Iannuzzi et al. [13], retrospectively reviewed 9165 acute un-TBAD patients (95\% best medical therapy; $2.9 \%$ TEVAR; $2 \%$ open repair). Analysis revealed acute un-TBAD patients treated with TEVAR have a significantly lower $(\mathrm{P}<0.01)$ all-cause mortality of $19 \%$ when compared to other treatment modalities (37\% best medical therapy and $34 \%$ open surgical repair). Median follow-up periods for the 3 treatment groups were 1.5 years or longer.

A retrospective study by Xiang et al. [14] included 357 acute un-TBAD patients (191 TEVAR and 166 BMT). The median follow-up duration for both groups was at least 3 years. The freedom from all-cause mortality 
at 1-, 3- and 5-years in the TEVAR group was significantly higher $(\mathrm{P}=0.028)$ than the BMT group. The conclusion was acute un-TBAD patients treated by TEVAR showed a lower all-cause mortality in the midto long-term than BMT treatment and/or open surgery.

Prospective studies and randomized controlled trials, also provide valuable supporting evidence for allcause mortality in TEVAR-treated un-TBAD patients. Firstly, the INvestigation of STEnt Grafts in Aortic Dissection trial (INSTEAD) [15] aimed to distinguish the mid-term results between 140 un-TBAD patients, randomized into 2 different groups (72 TEVAR and OMT versus 68 OMT only). Over a follow-up period of 2 years, data collected from the study showed that there was no significant difference between the 2 groups in terms of all-cause mortality (survival probability $95.6 \% \pm 2.5 \%$ OMT versus $88.9 \% \pm 3.7 \%$ TEVAR; $\mathrm{P}=0.15$ ). The follow-up INSTEAD-XL trial, over 5 years, showed the risk of all-cause mortality was significantly lower $(\mathrm{P}=0.13)$ for TEVAR and OMT than OMT alone (11.1\% versus $19.3 \%$ respectively) [16]. However, selection criteria for the INSTEAD trial also included chronic un-TBAD patients (2 to 52 weeks after onset), which is irrelevant to the scope of this present review. Secondly, the prospective randomized ADSORB trial [17] focused on acute un-TBAD patients $(n=61)$. Randomization in the allocation of patients was 31 patients in the TEVAR + BMT group and 30 in the BMT only group. It is reported that at 1-year there was only one death in the TEVAR group. Again, data from the studies indicate a lower all-cause mortality for TEVAR, further proving its superiority.

Several systematic review and meta-analyses have attempted to summarize the findings of observational and interventional studies in order to identify the best treatment for un-TBAD. One such review [18] which included 6 studies, reported that overall, there was no significant difference in all-cause mortality at 1 year ( $5.1 \%$ versus $5.4 \%, \mathrm{P}=0.96)$ nor 5 years $(15.3 \%$ versus $26.3 \%, \mathrm{P}=0.75)$ between acute un-TBAD patients that received TEVAR or best medical therapy. Contrastingly, another systematic review and meta-analysis by Hossack et al. [19], which also included six studies, reported that the risk of late ( $>30$ days) all-cause mortality was significantly lower $(\mathrm{P}<0.001)$ for acute un-TBAD patients who received TEVAR and BMT when compared to those treated with BMT only.

Evaluating the outcome of mid- to long-term all-cause mortality in the findings of the various studies, reviews and analyses demonstrates that the treatment of choice for un-TBAD regardless of time of symptom onset within the first 90 days (acute or subacute) should be TEVAR.

\section{Aorta-related mortality and rupture}

Despite gaining consensus for superior long-term outcomes, TEVAR may cause late aortic adverse events which sometimes do lead to mortality. The cumulative freedom from aortic-related adverse events was reported as $71.8 \%$ at 5 years post-TEVAR [12]. Numerous studies reported late aortic-specific mortality, which commonly resulted from aortic rupture and to a lesser extent retrograde type A dissection (RTAD).

The most notable clinical trials investigating TEVAR versus OMT for un-TBAD are the INSTEAD, INSTEAD-XL and the ADSORB trials. The ADSORB trial reported no aortic rupture or aortic-related mortality within the first year post-TEVAR [17]. The INSTEAD-XL trial had a $6.9 \%$ aortic-specific mortality rate $(5 / 72)$ in the first year of follow-up in the TEVAR group. Yet, there were no aortic-related deaths over the next four years of follow-up suggesting an optimal aortic-specific survival in the long term [16].

Observational studies investigating patients with acute un-TBAD undergoing TEVAR reported varying aortic-specific mortality rates, resulting mainly from rupture. A study by Xiang and colleagues [14], who proposed performing TEVAR in the acute phase of un-TBAD, showed freedom from aortic-related death at 1and 5-years post-TEVAR as $97.8 \%$ and $94.1 \%$, respectively. Further, Qin et al. [12] revealed an aortic-related mortality rate of $4.3 \%(8 / 184)$ over 29 months of follow-up. Both studies reported significant post-TEVAR aortic-related survival over OMT $(\mathrm{P}<0.05)$. Another study by Nakamura et al [20], who offered TEVAR during the subacute phase of dissection, ascertained the aortic-related mortality by reporting a rate of $4 \%$ over 37 months of follow-up. 
Rupture and RTAD were the most commonly reported causes of aortic-related death in patients who underwent TEVAR for unTBAD. Rupture is associated with high mortality at the indexed event [21]. Other observational studies reported the incidence of aortic rupture to be $2.5 \%-5 \%$ [12, 14, 20]. Xiang et al. [14] showed a cumulative incidence rate of aortic rupture of $2.1 \%$ after 1-year and $5.1 \%$ after 5 -years of followup. These variations in the incidence could be attributed to the different follow-up periods and timings of intervention adopted in each respective study.

Some studies reported the influence of different timings of interventions on the rate of post-TEVAR aorticrelated mortality. A study by Tjaden and colleagues [6], with a mean follow-up of 26 months, showed that TEVAR in the acute phase of unTBAD was associated with more aortic-related mortality than in the chronic phase (2.7 vs. $2.1 ; \mathrm{P}=1.0$ ). In the same study, four cases of post-TEVAR aortic rupture occurred only in the acute group of intervention.

Xie and colleagues [8], demonstrated that aortic-related death is more likely to occur in the subacute than the acute intervention group ( $4.5 \%$ vs. $2.5 ; \mathrm{P}=0.5)$. They also showed that risk of aortic rupture was higher in the subacute group ( $3.8 \%$ vs. $1.7 \% ; \mathrm{P}=0.45)$. Similarly, Xiang et al. [9] demonstrated that aortic-related mortality was higher in the subacute intervention group than in the acute group $(6.8 \%$ vs. $5.2 \% ; \mathrm{P}=.86)$ five years post-TEVAR.

Three meta-analyses presented data on the long-term aortic-related outcomes in TBAD patients who underwent TEVAR versus OMT. Li and colleagues [22] demonstrated superior benefit in long-term survival with TEVAR compared to OMT (HR $=0.71 ; 95 \%$ CI: 0.52-0.95). Furthermore, this meta-analysis demonstrated that TEVAR for TBAD was protective from later rupture compared to OMT $(\mathrm{OR}=0.21 ; 95 \% \mathrm{CI}$ : 0.10-0.43). Another meta-analysis of four studies showed lower rates of aortic rupture post-TEVAR (TEVAR group 3.5\%, OMT group 9.4\%), which again demonstrated the OMT group has higher risks of rupture in the long term (OR $2.49 \mathrm{P}=0.01$ ) [18]. The third meta-analysis by Hossack et al. [19] proved the significant benefit of TEVAR in protecting un-TBAD patients from late aortic adverse events compared to OMT (HR $1.56,95 \%$ CI $1.14-2.13)$.

The presented data gives an understanding into the aortic-related survival in the long-term. However, there remains a paucity of robust evidence on the long-term aortic-specific mortality post-TEVAR in patients with acute un-TBAD. It is worth noting that, however, multiple studies showed both selection bias and significant loss of patients during follow-up. Finally, many studies reported mortalities due to unknown causes, which may affect actual rate of aortic-specific mortality.

\subsection{Aortic-specific events:}

\subsubsection{Late Endoleaks}

Late or secondary endoleaks are defined as endoleaks occurring 30-days post-TEVAR [23]. Of the five endoleak types described, type I endoleak occurs when the blood flows alongside the graft's proximal (Ia) or distal (Ib) attachments to the arterial wall. Type II endoleak describes a backward flow from a single (IIa) or multiple (IIb) side branches as the intercostal or lumbar arteries into the false lumen [24, 25]. Type I and Type II endoleaks are the most commonly observed endoleaks during later follow-up after TEVAR in un-TBAD $[8$, $12,21,26]$.

Some endoleaks such as type Ia and Ib can eventually resolve on their own without any need for re-intervention $[12,27]$. However, some endoleaks persist and will perfuse the FL, leading to progressive aortic expansion due to endotension created

An earlier study by $\mathrm{Xu}$ et al. reported 3 deaths from thoracic aortic rupture due to overlooked endoleaks in patients managed with TEVAR in the chronic phase of dissection [28]. However, recent studies focusing on intervention in the acute phase showed no endoleak-specific mortality. This might be attributed to the use of renovated grafts and technologically advanced practice. Table (2) summarizes the reported incidence of endoleaks after TEVAR in several studies identified. 
Time from symptom onset of a TBAD to intervention with TEVAR has not shown any association with endoleak development, for example, Xie et al. [8] reported no significant difference in incidence of endoleak between acute and subacute intervention groups. Endoleaks can be treated with careful monitoring if no significant increase in aortic diameter is observed. Still, re-intervention should be considered in those with perfusion of the FL or an unsealed primary entry tear due to the high risk of aortic rupture and associated mortality. Further improvement in stents and practice might be able to decrease the incidence of endoleak and yield more satisfying outcomes.

\subsubsection{Retrograde Type A aortic dissection (RTAD)}

Retrograde type A aortic dissection (RTAD) is a life-threatening complication which is defined by Estrera et al. as a dissection originating distal to the ascending aorta but extending backwards with a retrograde flap into the ascending aorta [27, 29]. Iatrogenic proximal Stent graft induced new entry (SINE) is a potential aetiology of RTAD following TEVAR for unTBAD $[12,28]$. Though it has a rare incidence that ranges between $1.33 \%-3.17 \%[27,30,31]$, it has a high mortality rate (42\%) [27].

RTAD post-TEVAR can present acutely during the TEVAR, however, most can take several months to present $[27,31,32]$. RTAD must be suspected during follow-up in acute-onset or recurrent chest pain cases [31]. However, it may present silently and be discovered incidentally on follow-up imaging [32, 33]. A metaanalysis by Chen et al. [34], included both complicated and uncomplicated dissections and showed that patients treated with proximal bare stent were more likely to have RTAD than those treated with proximal non-bare stent-grafts . (2.31\% vs. $1.24 \%$; $\mathrm{RR}=2.06 ; 95 \% \mathrm{CI}, 1.22-3.50)$. This was contradicted later by Ma et al. [31], indicating no significant difference in the incidence of RTAD between proximal bare and non-bare stent-graft groups (Bare: $3.4 \%$ vs. non-bare $2.8 \%, \mathrm{P}=0.64$ ).

Ma et al. [31] also showed a very high mortality rate associated with RTAD; 7 out of 27 (25\%) patients had aorta-related sudden death due to rupture or cardiac tamponade. In contrast, five other deaths occurred postoperatively due to multiple organ failure. The mortality rate in this study was $(44.4 \%)$ which further validated the results of Eggebrecht et al., who reported a mortality rate of $42 \%$ [27, 31].

Dissection characteristics, grafting procedure, and genetics were shown to influence the incidence of RTAD after TEVAR in patients with TBAD. Demographics, however, were not associated with an increased risk of RTAD. Still, patients with Marfan syndrome experienced more complications and were at a higher risk of developing RTAD (OR: 3.7; 95\%CI 1.09-12.75) [31].

An ascending thoracic aortic diameter $>4 \mathrm{~cm}$ ( $47 \%$ in RTAD vs. $21 \%$ in no-RTAD patients, $\mathrm{P}=.05$ ) [32] and a proximal aortic tear on the concave surface of the arch [35] were shown to be dissection-related predisposing factors for RTAD. Further, the FL tended to be consistently larger at the levels of the left subclavian artery in patients with RTAD (RTAD patients: $3.2 \mathrm{~mm}$; no-RTAD patients $2.2 \mathrm{~mm} ; \mathrm{P}=.3$ ), [32].

Stent-graft-related risks included a proximal landing zone 1 or 2 , which can induce a proximal new re-entry tear [32]. In addition, stent-graft size $<165 \mathrm{~mm}$ was reported to be predictive of RTAD following TEVAR (OR:2.99; 95\% CI 1.35-6.64) [31].

There is a reported increased risk of RTAD in patients undergoing TEVAR in the acute rather than the chronic stage of dissection. (RR: 1.81; 95\% CI, 1.04-3.14) [31], this result can be explained by the fragility of the aortic wall during the acute phase. However, this concept was challenged recently in 2 studies that showed that the intervention timing did not influence the incidence of RTAD in their TBAD study population [8, $32]$.

RTAD is a very serious complication following TEVAR that often necessitates further high risk procedures such as total arch replacement and a frozen elephant trunk (An et al. 2018). Accurate stent-graft oversizing and play a vital role in minimizing the risk of RTAD in un-TBAD patients undergoing TEVAR [36]. The reported risks come from separate studies with variable sample sizes, putting them at a greater risk of underor over-estimating effects. Yet, these should be considered carefully so that patients may benefit from more focused care. 


\subsubsection{Stent graft-induced new entry (SINE)}

Dong and colleagues defined SINE as a new tear in the aortic intima induced by the TEVAR stent-graft postintervention. Proximal SINE is defined as a tear proximal to the stent-graft implanted, leading to RTAD or proximal pseudoaneurysm [37]. Distal SINE (dSINE) occurs distal to the stent-graft landing zone resulting in increased pressure in the FL, leading to further expansion in its diameter [37]. The occurrence of SINE has been frequently reported particularly following TEVAR in un-TBAD [12, 21, 28], with a distal SINE being the most commonly observed type [8, 12, 21, 38].

SINE is considered a dangerous complication of TEVAR, especially since it is usually asymptomatic and incidentally discovered with routine surveillance [39-41]. SINE can also lead to treatment failure as it prevents FL thrombosis by re-establishing its perfusion and subsequently hindering the favourable aortic remodelling [38].

Distal SINE is rarely observed immediately after TEVAR. However, longer follow-up yielded a concerning incidence of $6.22 \%-26.5 \%$ with a mean time for occurrence between $27.78-29.7$ months post-procedure [31, $38,42]$.

Predictors of dSINE were TEVAR in the chronic phase (OR: 2.6; 95\% 31.22-5.68; $\mathrm{P}=.01$ ), stent grafts with connecting bar (OR: 3.28; 95\%CI 1.54-7.0; $\mathrm{P}<.0$ ) and stent grafts size $<165 \mathrm{~mm}$ (OR:5.65; 95\%CI 2.6012.64; $\mathrm{P}<.01$ ) [31]Furthermore, Jang et al. [42] showed that distal oversizing is an independent predictor of dSINE, and proposed accurate stent-graft size selection may reduce the incidence of late dSINE. Medical management can be considered as a treatment option for dSINE, provided that structural stability is present. However, re-intervention is commonly indicated due to increased FL diameter, rupture, pseudoaneurysm or malperfusion [31, 42, 43].

Reintervention with TEVAR in TBAD patients can improve long-term survival. Nevertheless, recurrence rates of dSINE were high after TEVAR reintervention. More tapered stent-grafts and improved techniques may facilitate lower recurrence rates [43].

\subsection{Aortic Remodelling}

Aortic remodelling is a term which describes the desirable morphologic changes in the aortic anatomy following TEVAR. The parameters used to identify remodelling are false lumen (FL) thrombosis, FL regression, true lumen (TL) expansion, and maximum aortic diameter stability [1,27]. Several studies have validated the surveillance of these morphologic characteristics as significant predictors of outcomes in TBAD [16, 17, 27, 44]. Whilst there is evidence suggesting pre-emptive TEVAR in patients with un-TBAD [5, 45], assessment of aortic remodelling is vital in monitoring the post-procedural course of the dissection process and predicting outcomes [46, 47].

The FL is the most dangerous element in the process of aortic dissection. Its patency and hence perfusion (with elevated intraluminal pressure) contribute to the aortic expansion.. Furthermore, it may compress the TL and impair the blood flow to distal organs, causing malperfusion [48-50]. Endo-graft placement by TEVAR seals the primary entry tear and decreases the pressure within the FL, hopefully leading to both FL thrombosis and TL expansion [16]. FL thrombosis has a significant clinical value in the follow-up of patients with un-TBAD following TEVAR [16, 17]. Any FL thrombosis can be assessed by the absence of contrast media by a Computerised tomogram. However, Clough et al. [51] challenged this modality for assessment of FL and showed that magnetic resonance imaging with a blood pool agent has more accuracy in detecting thrombosis in FL.

Following TEVAR, the surveillance of FL thrombosis is critical in evaluating aortic stability and remodelling. Persistent FL perfusion or aneurysmal expansion might be an indication of stent graft failure, and warrant further reintervention $[52,53]$.

Different segments in the dissected thoracic and abdominal aorta exhibit variable degrees of remodelling. The proximal anatomical zones demonstrating the greatest favourable remodelling following TEVAR [54]. 
The FL thrombosis was shown to be more prominent in the thoracic dissecting aorta with less remodelling observed in the abdominal aorta irrespective of the timing of TEVAR [55]. Kamman et al. [44] showed that FL complete thrombosis in the distal zones (presented as $>20 \mathrm{~cm}$ from LSA origin) could be as low as $22 \%$. Similar findings were seen by Yuan et al. [5], who showed a superior FL thrombosis rate in the thoracic aorta compared to abdominal segments, especially in patients treated in the chronic phase of the disease. The overall occurrence of FL thrombosis in the dissected thoracic aortic segment increases with time after TEVAR [54]. Table (3) shows the degree of FL thrombosis reported in different studies according to the follow-up period.

\subsubsection{Timing of TEVAR and Aortic Remodelling}

Several studies showed that the long-term aortic remodelling is influenced by the timing of intervention and the different zones of dissection. This was addressed in a recent review by Jubouri et al. [4] who summarised the evidence in the literature on timing on TEVAR in relation with results, and concluded that performing TEVAR during the subacute phase of un-TBAD yield optimum results, with those being comparable to the acute phase but superior to the chronic phase. A comparative study demonstrated a post-TEVAR reduction in the maximum aortic diameter in the acute and early chronic groups $(-4.3 \pm 9.3$ vs. $-5.2 \pm 6.9)$. In contrast, the late chronic group showed a significant increase in the maximum thoracic aortic diameter post-TEVAR. $(2.5 \pm 4.6 \mathrm{~mm}, \mathrm{P}<0.001)$ [56]. Similarly, Torrent and colleagues [7] reported a non-significant difference in the degree of dissection extension between interventions in the acute vs. subacute stages of TBAD.

The VIRTUE registry showed a significant reduction in FL area in acute and subacute groups compared to the chronic group [54]. Patients with acute TBAD showed a more consistent degree of remodelling (thoracic FL thrombosis in $80 \%$ to $90 \%$ ) than those with a chronic TBAD (38\% to 91\%) following TEVAR [55]. Yuan and colleagues [5] further validated these results, concluding that the first three months after the onset of symptoms of TBAD represented the optimal aortic plasticity for intervention for remodelling post-TEVAR.

While timing showed no association with FL thrombosis in the proximal and distal descending thoracic aortic zones $(\mathrm{P}>0.3)$, FL thrombosis inferior to the diaphragm was significantly lower in patients with a chronic $\operatorname{TBAD}(\mathrm{P}=0.035)[54]$.

True lumen expansion results from the stent-graft placed within the TL of the thoracic aorta covering the primary entry tear. By sealing off the primary entry tear, it provides scaffolding support and ensures blood flows distally within the TL. The ADSORB trial [17] showed a significant increase in TL diameter and reduction in FL diameter within the first year of follow-up following TEVAR. Yet, the INSTEAD-XL trial [16] required a five-year follow-up to demonstrate this significant difference. This difference could be attributed to the timing of patient enrolment in both trials as the ADSORB trial patients were enrolled during the acute phase of dissection ( $<14$ days). Those in the INSTEAD-XL trial were recognized as stable and were enrolled during the subacute phase. Conversely, results from the VIRTUE registry [54] showed that the TL expansion was not related to the timing of TEVAR. Another study by Andacheh et al. [57] showed that the rate at which the TL expands after TEVAR is not parallel to that at which the FL shrinks; the expansion of the TL plateaued after 12 months, while the shrinkage in the FL continued beyond 12 months post-TEVAR. This can further ascertain the assumption that most of the TL expansion is attributed to the scaffolding effect of the stent-graft implantation.

Although the FL regression and the TL expansion seem to demonstrate a significant change following the treatment with TEVAR, this is not the case with the reduction in the maximum aortic diameter. In fact, some studies showed a further slight expansion of the maximum aortic diameter [52, 58]. See table (3)

Although FL thrombosis is considered as a primary predictor of aortic remodelling, there is evidence not all thrombosed FLs have positive remodelling outcomes. A study by Kitamura showed post-TEVAR FL thrombosis was achieved in $74 \%$, whilst only $47 \%$ achieved descending thoracic aortic remodelling. Therefore, descending aorta remodelling was reported to remain uncertain, especially when associated with an initially large aortic diameter [59]. 
Another study by Omura et al. [58], patients with un-TBAD in the acute-subacute timing exhibited smaller aortic diameter. All the patients offered TEVAR in this time period showed significant shrinkage of the proximal aorta. However, distal to the stent-graft, shrinkage was observed in $50 \%$ only. This study has demonstrated the importance of radiological surveillance post-TEVAR. Up to $17.8 \%$ who underwent TEVAR showed aortic dilation at the distal landing zone [58]. Furthermore, Xie et al. [8] studied abdominal and thoracic FL as separate entities in the follow-up and showed greater than $50 \%$ have a patent abdominal aortic FL post-TEVAR in both the acute and subacute phases. Several other studies established this segmentspecific approach for the long-term evaluation of aortic remodelling and FL thrombosis [8, 44].

The surveillance of the aortic parameters might be as vital as the primary intervention for the long-term outcomes. Careful assessment of the aortic diameter and the degree of FL thrombosis over time can be very informative about the natural history of the underlying dissection and its sequelae. The risk of developing dSINE must be considered when evaluating an expanding aortic diameter post-TEVAR. The emerging data concerning the aortic expansion distal to the stent-graft needs further investigation and follow-up to better understand the long-term outcomes following TEVAR.

\subsection{TEVAR Reintervention}

Recent studies have estimated the need for reintervention at $5 \%$ of those undergoing TEVAR for un-TBAD $[14,21,53,60]$. The indications for late re-intervention are varied (Table 4). Specifically, Qin et al. [12] defined adverse events requiring re-intervention as a total thoracic aortic diameter enlargement $>60 \mathrm{~mm}$, RTAD, rupture, ulcer-like projection, SINE or persistent endoleak with enlargement. Similarly, Nienaber et al. [16] identified other indications such as an enlarging total aortic diameter over $55 \mathrm{~mm}$ or malperfusion.

It seems endoleaks, aortic expansion and SINE are the most commonly reported indications for re-intervention $[12,21,28]$. Reintervention within 1-year was more likely to be indicated in acute un-TBAD patients when compared to interventions performed in the subacute phase. Matched analysis, showed the acute TBAD re-intervention rates were significantly higher $(\mathrm{P}=0.007)[7]$.

A large retrospective cohort study showed that the re-intervention rate following TEVAR for un-TBAD is $(41 / 751 ; 5.46 \%)$ [21]. Thoracic stent grafting has a lower reintervention rate when compared to other treatment modalities and a meta-analysis by $\mathrm{Li}$ et al. [22] revealed a significant difference in late re-intervention $(\mathrm{OR}=0.33 ; 95 \% \mathrm{CI}: 0.13-0.85)$. This meta-analysis also showed that TEVAR is associated with a significantly reduced rate of re-intervention, late rupture (OR $=0.21 ; 95 \% \mathrm{CI}: 0.10-0.43)$, and aneurysmal dilatation/expansion ( $\mathrm{OR}=0.15 ; 95 \% \mathrm{CI}$ : 0.04-0.63) during follow-up

\section{Should "Uncomplicated" TBAD really exist?}

A significant number of un-TBAD patients on OMT alone, may require further complex intervention with TEVAR due to progression of the dissection. Currently, only un-TBAD patients who meet certain criteria making them "high-risk" for aorta-related complications without immediate risk of rupture or malperfusion are offered pre-emptive TEVAR [4]. These high-risk criteria are an initial aortic diameter of $>40 \mathrm{~mm}$, an entry tear $>10 \mathrm{~mm}$, an associated FL diameter of $>22 \mathrm{~mm}$, and a free-floating TL [5, 61]. Although it is worth noting that these criteria vary slightly in different international guidelines with no uniformity for intervention. Despite not exhibiting evidence of rupture or malperfusion this raises the question whether or not it is correct to categorise these patients as un-TBAD. In addition, given both co-TBAD and un-TBAD have identical underlying pathology, also given that pre-emptive TEVAR for un-TBAD has proven its safety and effectiveness, is it wise to continue using the complications-based classification system?

\section{Conclusion}

The introduction of TEVAR for un-TBAD has shifted the paradigm of clinical practice. Thoracic stent grafting has proven to be a safe and effective treatment modality for un-TBAD by providing favourable mid- and long-term survival outcomes, including complications, and aortic remodelling. Overall, it can be concluded that with further research, pre-emptive TEVAR could be considered first-line treatment in all un-TBAD patients rather than just those classed as high-risk. 
Table 1. Summary of Section 2.1 studies.

\begin{tabular}{llll}
\hline Year & Author & Study Type & Size \\
\hline 2009 & Nienaber et al. & Clinical trial & Total: 140 TEVAR \\
& with OMT: 72 \\
& & OMT only: 68 \\
& & \\
& & \\
& & \\
& & \\
& Nienaber et al. & Clinical trial & Total: 140 TEVAR \\
& (INSTEAD-XL) & & OMT only: 68
\end{tabular}

Summary

No significant

difference in

all-cause mortality

at 2 years between

TEVAR with OMT

and OMT only

groups $(\mathrm{P}=0.15)$.

Clinical tria

with OMT: 72

No significant

difference in

all-cause mortality

during follow-up

period (2-5 years)

between TEVAR

with OMT (11.1\%)

and OMT only

(19.3\%) groups

$(\mathrm{P}=0.13)$.

2014

Brunkwall et al.

Clinical trial

Total: 61 TEVAR

One death due to

(1-year Results of

the ADSORB Trial)

2016

Qin et al.

Observational study

with BMT: 30 BMT

only: 31

cardiac arrest in

TEVAR with BMT

group recorded.

Total: 338 TEVAR

Total of 50 late

with OMT: 184

OMT only: 154

(>30 days) deaths

observed (27

aortic-related; 18

unrelated to

dissection; 5

unknown).

All-cause mortality significantly lower

for TEVAR with

OMT group

$(\mathrm{P}=0.01)$.

Enezate et al.

Systematic review and meta-analysis
6 studies Total:

1960

No significant difference between BMT and TEVAR all-cause mortality in short-term (30 days; $\mathrm{P}=0.15$ ), intermediate (1 year; $\mathrm{P}=0.96$ ) and mid-term (2-5 years; $\mathrm{P}=0.75)$. 


\begin{tabular}{|c|c|c|c|c|}
\hline Year & Author & Study Type & Size & Summary \\
\hline 2018 & Tjaden Jr. et al. & Observational study & $\begin{array}{l}\text { Total: } 264 \text { Acute } \\
\text { TBAD: } 170 \\
\text { (un-TBAD 69; } \\
\text { co-TBAD 101) } \\
\text { Chronic TBAD: } 94 \\
\text { (un-TBAD 40; } \\
\text { co-TBAD 54) }\end{array}$ & $\begin{array}{l}\text { Overall all-cause } \\
\text { mortality is } 12.5 \% \\
\text { in follow-up period } \\
\text { (mean } 26 \text { months). } \\
\text { Significantly lower } \\
\text { all-cause mortality } \\
\text { rate for acute } \\
\text { TBAD (P=0.02). } \\
\text { Multivariate } \\
\text { analysis shows } \\
\text { overall survival } \\
\text { significantly higher } \\
\text { for acute un-TBAD } \\
(93 \%) \text { compared to } \\
\text { other subtypes } \\
(83 \%) \text { at } 2 \text { years } \\
(\mathrm{P}<0.05) .\end{array}$ \\
\hline 2018 & Iannuzzi et al. & Observational study & $\begin{array}{l}\text { Total: } 9165 \text { OMT: } \\
\text { 95\% TEVAR: } 2.9 \% \\
\text { Open repair: } 2 \%\end{array}$ & $\begin{array}{l}\text { 1-year survivals } \\
\text { (OMT: } 84 \% \text {; } \\
\text { TEVAR: } 85 \% \text {; Open } \\
\text { repair: } 76 \% \text { ) and } \\
\text { 5-year survivals } \\
\text { (OMT: } 60 \% \text {; } \\
\text { TEVAR: } 76 \% \text {; Open } \\
\text { repair: } 67 \% \text { ) } \\
(\mathrm{P}<0.01) \text {. } \\
\text { Risk-adjusted } \\
\text { multivariable } \\
\text { analysis shows } \\
\text { significantly } \\
\text { improved survival } \\
\text { for TEVAR } \\
\text { compared with } \\
\text { OMT (P<0.01) and } \\
\text { no significant } \\
\text { difference between } \\
\text { OMT and open } \\
\text { repair }(\mathrm{P}<0.01) \text {. }\end{array}$ \\
\hline 2020 & Hossack et al. & $\begin{array}{l}\text { Systematic review } \\
\text { and meta-analysis }\end{array}$ & $\begin{array}{l}6 \text { studies Total: } \\
\text { 14706 (TEVAR: } \\
1066 \text { ) }\end{array}$ & $\begin{array}{l}\text { Significantly lower } \\
\text { risk of all-cause } \\
\text { mortality }(\mathrm{P}<0.001) \\
\text { and aorta related } \\
\text { mortality }(\mathrm{P}=0.001) \\
\text { for TEVAR when } \\
\text { compared to BMT. }\end{array}$ \\
\hline
\end{tabular}




\begin{tabular}{|c|c|c|c|c|}
\hline Year & Author & Study Type & Size & Summary \\
\hline 2020 & Torrent et al. & Observational study & $\begin{array}{l}\text { Total: } 688 \text { Acute } \\
\text { un-TBAD: } 446 \\
\text { Subacute } \\
\text { un-TBAD: } 242\end{array}$ & $\begin{array}{l}\text { 1-year mortality for } \\
\text { acute and subacute } \\
\text { un-TBAD patients } \\
\text { undergoing TEVAR } \\
(13.3 \% \text { and } 8.2 \% \\
\text { respectively; } \\
\mathrm{P}=0.129) \text {. After } \\
\text { propensity score } \\
\text { matching 1- year } \\
\text { mortality for acute } \\
\text { and subacute } \\
\text { patients (12.4\% and } \\
9.9 \% \text { respectively; } \\
\mathrm{P}=0.5) .\end{array}$ \\
\hline 2020 & Bi et al. & Observational study & $\begin{array}{l}\text { Total: } 53 \text { Acute } \\
\text { TBAD with } \\
\text { TEVAR: } 22 \\
\text { Subacute TBAD } \\
\text { with TEVAR: } 18 \\
\text { Non-operative: } 13\end{array}$ & $\begin{array}{l}\text { 3-year survival rates } \\
\text { for acute TBAD } \\
\text { with TEVAR, } \\
\text { subacute TBAD } \\
\text { with TEVAR, } \\
\text { non-operative } \\
\text { groups }(95.5 \% \text {, } \\
100 \%, 85.7 \% \\
\text { respectively). }\end{array}$ \\
\hline 2021 & Spinelli et al. & Observational study & $\begin{array}{l}\text { Total: } 172 \text { Acute } \\
\text { un-TBAD with } \\
\text { TEVAR: } 70 \text { Acute } \\
\text { co-TBAD with } \\
\text { TEVAR: } 102\end{array}$ & $\begin{array}{l}\text { No significant } \\
\text { difference in overall } \\
\text { survival between } \\
\text { co-TBAD and } \\
\text { un-TBAD patients } \\
\text { at } 1 \text { year } \\
(88.8 \% \pm 11.2 \% \\
\text { versus } 96.8 \% \pm 3.1 \%) \\
\text { and } 3 \text { years } \\
(79.1 \% \pm 20.8 \% \text { vs } \\
90.4 \% \pm 9.5 \%), \\
(\mathrm{P}=0.138) .\end{array}$ \\
\hline 2021 & Xie et al. & Observational study & $\begin{array}{l}\text { Total: } 267 \text { Acute } \\
\text { un-TBAD: } 130 \\
\text { Subacute } \\
\text { un-TBAD: } 137\end{array}$ & $\begin{array}{l}\text { Cumulative survival } \\
\text { rate from all-cause } \\
\text { mortality at } 5 \text { years } \\
\text { for acute }(94.2 \% \text {; } \\
95 \% \text { CI } 89.1 \% \text { - } \\
95.7 \%) \text { and } \\
\text { subacute } \\
(88.3 \% ; 95 \% \text { CI } \\
81.5 \% \text { e } 95.7 \%) \\
\text { groups. No } \\
\text { significant difference } \\
\text { in all-cause } \\
\text { mortality between } \\
\text { the } 2 \text { groups (Log } \\
\text { rank } \mathrm{P}=0.24) .\end{array}$ \\
\hline
\end{tabular}




\begin{tabular}{|c|c|c|c|c|}
\hline Year & Author & Study Type & Size & Summary \\
\hline 2021 & Xiang et al. & Observational study & $\begin{array}{l}\text { Total: } 357 \text { TEVAR: } \\
\text { 191 BMT: } 166\end{array}$ & $\begin{array}{l}\text { Freedom from } \\
\text { all-cause mortality } \\
\text { higher in TEVAR } \\
\text { group than BMT } \\
\text { group at } 1(97.2 \% \\
\text { versus } 94.2 \%), 3 \\
(96.4 \% \text { versus } \\
88.5 \%) \text { and } 5 \text { years } \\
(91.9 \% \text { versus } \\
82.2 \%)(\mathrm{P}=0.028) .\end{array}$ \\
\hline 2021 & Xiang et al. & Observational study & $\begin{array}{l}\text { Total: } 238 \text { Acute } \\
\text { with TEVAR: } 142 \\
\text { Subacute with } \\
\text { TEVAR: } 96\end{array}$ & $\begin{array}{l}10 \text { all-cause death } \\
\text { in acute group } \\
\text { versus } 9 \text { in subacute } \\
\text { group at } 5 \text { years. } \\
\text { Landmark analysis } \\
\text { reveals comparable } \\
\text { all-cause mortality } \\
\text { rates between } 2 \\
\text { groups at } 1 \text { year } \\
(\mathrm{P}=0.38) \text { and } \\
\text { between } 1-5 \text { years } \\
(\mathrm{P}=0.15) \text {. }\end{array}$ \\
\hline
\end{tabular}

Table 2. Aortic-specific mid and long term outcomes of un-TBAD in the TEVAR arms.

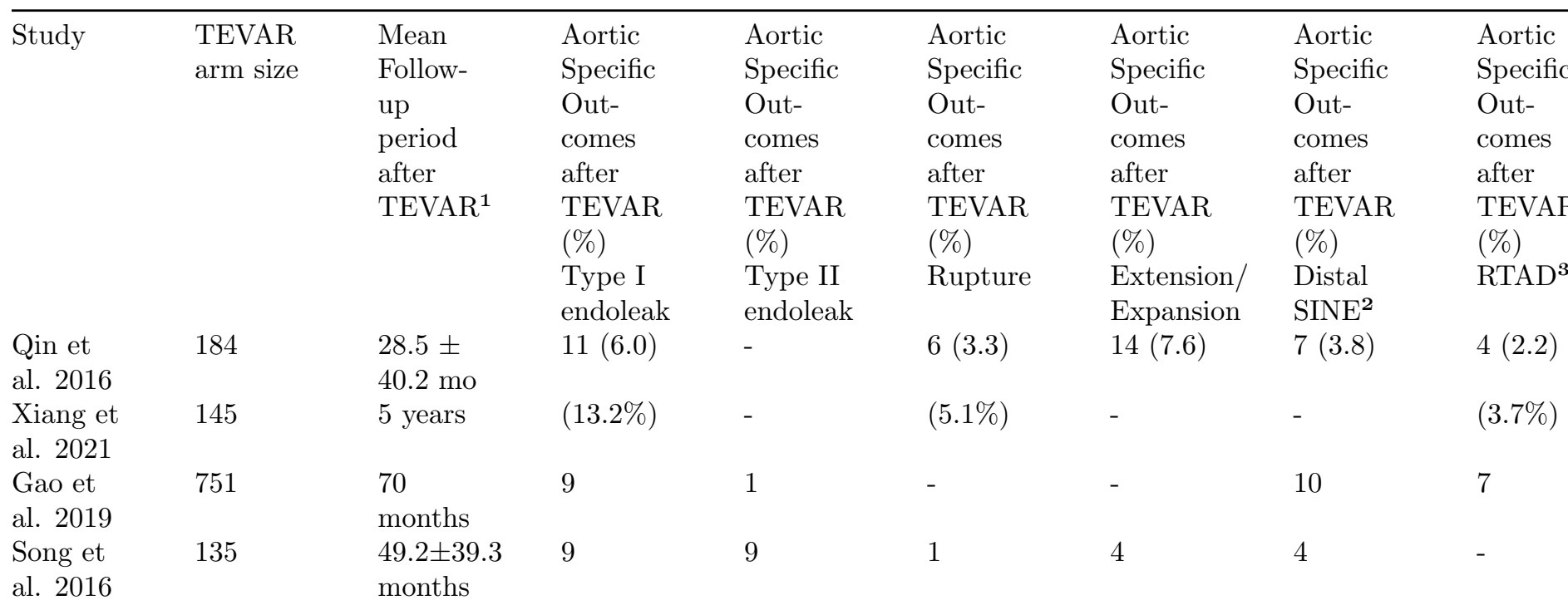




\begin{tabular}{|c|c|c|c|c|c|c|c|c|}
\hline${ }^{1}$ TEVAR: & ${ }^{1} \mathrm{TEVAR}:$ & ${ }^{1}$ TEVAR: & ${ }^{1} \mathrm{TEVAR}:$ & ${ }^{1}$ TEVAR: & ${ }^{1}$ TEVAR: & ${ }^{1}$ TEVAR: & ${ }^{1}$ TEVAR: & ${ }^{1} \mathrm{TEVA}$ \\
\hline $\begin{array}{l}\text { Thora- } \\
\text { cic }\end{array}$ & $\begin{array}{l}\text { Thora- } \\
\text { cic }\end{array}$ & $\begin{array}{l}\text { Thora- } \\
\text { cic }\end{array}$ & $\begin{array}{l}\text { Thora- } \\
\text { cic }\end{array}$ & $\begin{array}{l}\text { Thora- } \\
\text { cic }\end{array}$ & $\begin{array}{l}\text { Thora- } \\
\text { cic }\end{array}$ & $\begin{array}{l}\text { Thora- } \\
\text { cic }\end{array}$ & $\begin{array}{l}\text { Thora- } \\
\text { cic }\end{array}$ & $\begin{array}{l}\text { Thora- } \\
\text { cic }\end{array}$ \\
\hline $\begin{array}{l}\text { Endo- } \\
\text { vascular }\end{array}$ & $\begin{array}{l}\text { Endo- } \\
\text { vascular }\end{array}$ & $\begin{array}{l}\text { Endo- } \\
\text { vascular }\end{array}$ & $\begin{array}{l}\text { Endo- } \\
\text { vascular }\end{array}$ & $\begin{array}{l}\text { Endo- } \\
\text { vascular }\end{array}$ & $\begin{array}{l}\text { Endo- } \\
\text { vascular }\end{array}$ & $\begin{array}{l}\text { Endo- } \\
\text { vascular }\end{array}$ & $\begin{array}{l}\text { Endo- } \\
\text { vascular }\end{array}$ & $\begin{array}{l}\text { Endo- } \\
\text { vascula }\end{array}$ \\
\hline Aortic & Aortic & Aortic & Aortic & Aortic & Aortic & Aortic & Aortic & Aortic \\
\hline $\begin{array}{l}\text { Repair, } \\
{ }^{2} \text { SINE: }\end{array}$ & $\begin{array}{l}\text { Repair, } \\
{ }^{2} \text { SINE: }\end{array}$ & $\begin{array}{l}\text { Repair, } \\
\text { 2SINE: }\end{array}$ & $\begin{array}{l}\text { Repair, } \\
{ }^{2} \text { SINE: }\end{array}$ & $\begin{array}{l}\text { Repair, } \\
\text { 2SINE: }\end{array}$ & $\begin{array}{l}\text { Repair, } \\
{ }^{2} \text { SINE: }\end{array}$ & $\begin{array}{l}\text { Repair, } \\
\text { 2SINE: }\end{array}$ & $\begin{array}{l}\text { Repair, } \\
\text { 2SINE: }\end{array}$ & $\begin{array}{l}\text { Repair, } \\
\text { 2SINE: }\end{array}$ \\
\hline Stent- & Stent- & Stent- & Stent- & Stent- & Stent- & Stent- & Stent- & Stent- \\
\hline Induced & Induced & Induced & Induced & Induced & Induced & Induced & Induced & Induced \\
\hline New & New & New & New & New & New & New & New & New \\
\hline Entry, & Entry, & Entry, & Entry, & Entry, & Entry, & Entry, & Entry, & Entry, \\
\hline${ }^{3}$ RTAD: & ${ }^{3}$ RTAD: & ${ }^{3}$ RTAD: & ${ }^{3}$ RTAD: & ${ }^{3}$ RTAD: & ${ }^{3}$ RTAD: & ${ }^{3}$ RTAD: & ${ }^{3}$ RTAD: & ${ }^{3} \mathrm{RTAD}$ \\
\hline $\begin{array}{l}\text { Retro- } \\
\text { grade }\end{array}$ & $\begin{array}{l}\text { Retro- } \\
\text { grade }\end{array}$ & $\begin{array}{l}\text { Retro- } \\
\text { grade }\end{array}$ & $\begin{array}{l}\text { Retro- } \\
\text { grade }\end{array}$ & $\begin{array}{l}\text { Retro- } \\
\text { grade }\end{array}$ & $\begin{array}{l}\text { Retro- } \\
\text { grade }\end{array}$ & $\begin{array}{l}\text { Retro- } \\
\text { grade }\end{array}$ & $\begin{array}{l}\text { Retro- } \\
\text { grade }\end{array}$ & $\begin{array}{l}\text { Retro- } \\
\text { grade }\end{array}$ \\
\hline Type A & Type A & Type A & Type A & Type A & Type A & Type A & Type A & Type A \\
\hline Aortic & Aortic & Aortic & Aortic & Aortic & Aortic & Aortic & Aortic & Aortic \\
\hline Dissecti- & Dissecti- & Dissecti- & Dissecti- & Dissecti- & Dissecti- & Dissecti- & Dissecti- & Dissecti \\
\hline on, & on, & on, & on, & on, & on, & on, & on, & on, \\
\hline 4Data & 4Data & 4Data & 4Data & 4Data & 4Data & 4Data & 4Data & 4Data \\
\hline pre- & pre- & pre- & pre- & pre- & pre- & pre- & pre- & pre- \\
\hline sented & sented & sented & sented & sented & sented & sented & sented & sented \\
\hline accord- & accord- & accord- & accord- & accord- & accord- & accord- & accord- & accord- \\
\hline ing to & ing to & ing to & ing to & ing to & ing to & ing to & ing to & ing to \\
\hline number & number & number & number & number & number & number & number & number \\
\hline & of & of & of & of & of & of & of & of \\
\hline patients & patients & patients & patients & patients & patients & patients & patients & patier \\
\hline com- & com- & com- & com- & com- & com- & com- & com- & com- \\
\hline pleted & pleted & pleted & pleted & pleted & pleted & pleted & pleted & pleted \\
\hline the & the & the & the & the & the & the & the & the \\
\hline follow- & follow- & follow- & follow- & follow- & follow- & follow- & follow- & follow- \\
\hline & up & up & up & up & up & up & up & up \\
\hline period. & period. & period. & period. & period. & period. & period. & period. & period. \\
\hline - & - & - & - & - & - & - & - & - \\
\hline
\end{tabular}

Table 3. Morphological outcomes over time:

Study

Nienaber et al. 2013

Tang et al. 2020

Jia et al. 2013

Xia et al. $2021^{* *}$

The values represents the maximum lumen diameter, ? The false lumen thrombosis results concords with the follow-up peri

Table 4. Indications for Re-Intervention: 


\begin{tabular}{|c|c|c|c|c|}
\hline Study & TEVAR arm size & Follow-up period & $\begin{array}{l}\text { Required } \\
\text { re-intervention } \\
(\%)\end{array}$ & $\begin{array}{l}\text { Indication for } \\
\text { re-intervention }\end{array}$ \\
\hline Jia et al. 2013 & 208 & 28.5 months & $9(4.3 \%)$ & $\begin{array}{l}\text { Persistent endoleak } \\
(3 / 9) 6 \text { Rupture of } \\
\text { descending aorta } \\
(6 / 9)\end{array}$ \\
\hline Xiang et al. 2021 & 191 & 5 years & $6(4.1 \%)$ & $\begin{array}{l}\text { RTAD }(2 \text { of } 6) \text { Type } \\
\text { I endoleak }(2 / 6) \\
\text { Dissection extension } \\
(1 / 6) \text { AAA } \\
\text { expansion }(1 / 6)\end{array}$ \\
\hline $\begin{array}{l}\text { Mizoguchi et al. } \\
2017\end{array}$ & 36 & $41 \pm 21$ months & $2(5.2 \%)$ & $\begin{array}{l}\text { Type Ia endoleak } \\
(2 / 2)\end{array}$ \\
\hline Gao et al. 2019 & 751 & $\begin{array}{l}70 \text { months* (IQR } \\
48.8)\end{array}$ & $4.46 \%$ & $\begin{array}{l}\text { RTAD }(7 / 41) \\
\text { Endoleak }(10 / 41) \\
\text { Distal SINE }(10 / 41) \\
\text { Residual dissec- } \\
\text { tion/recurrence of } \\
\text { symptoms }(8 / 41) \\
\text { Penetrating aortic } \\
\text { ulcer }(1 / 41) \\
\text { Aneurysm }(3 / 41) \\
\text { False aneurysm } \\
(2 / 41)\end{array}$ \\
\hline aT: Acute & aT: Acute & aT: Acute & aT: Acute & aT: Acute \\
\hline management by & management by & management by & management by & management by \\
\hline $\begin{array}{l}\text { TEVAR (1-14 } \\
\text { days from } \\
\text { presentation), sT: }\end{array}$ & $\begin{array}{l}\text { TEVAR (1-14 } \\
\text { days from } \\
\text { presentation), sT: }\end{array}$ & $\begin{array}{l}\text { TEVAR (1-14 } \\
\text { days from } \\
\text { presentation), sT: }\end{array}$ & $\begin{array}{l}\text { TEVAR (1-14 } \\
\text { days from } \\
\text { presentation), sT: }\end{array}$ & $\begin{array}{l}\text { TEVAR (1-14 } \\
\text { days from } \\
\text { presentation), sT: }\end{array}$ \\
\hline $\begin{array}{l}\text { Subacute } \\
\text { manaoement by }\end{array}$ & Subacute & Subacute & Subacute & Subacute \\
\hline $\begin{array}{l}\text { management by } \\
\text { TEVAR }(15-90\end{array}$ & $\begin{array}{l}\text { management by } \\
\text { TEVAR }(15-90\end{array}$ & $\begin{array}{l}\text { management by } \\
\text { TEVAR (15-90 }\end{array}$ & $\begin{array}{l}\text { management by } \\
\text { TEVAR }(15-90\end{array}$ & $\begin{array}{l}\text { management by } \\
\text { TEVAR (15-90 }\end{array}$ \\
\hline $\begin{array}{l}\text { days from } \\
\text { presentation) } *\end{array}$ & $\begin{array}{l}\text { days from } \\
\text { presentation) } *\end{array}$ & $\begin{array}{l}\text { days from } \\
\text { presentation) }\end{array}$ & $\begin{array}{l}\text { days from } \\
\text { presentation) } *\end{array}$ & $\begin{array}{l}\text { days from } \\
\text { presentation) } *\end{array}$ \\
\hline Data Median & Data Median & Data Median & Data Median & Data Median \\
\hline reported, and & reported, and & reported, and & reported, and & reported, and \\
\hline $22.9 \%$ of the & $22.9 \%$ of the & $22.9 \%$ of the & $22.9 \%$ of the & $22.9 \%$ of the \\
\hline $\begin{array}{l}\text { cohort lost } \\
\text { follow-up in this }\end{array}$ & $\begin{array}{l}\text { cohort lost } \\
\text { follow-up in this }\end{array}$ & $\begin{array}{l}\text { cohort lost } \\
\text { follow-up in this }\end{array}$ & $\begin{array}{l}\text { cohort lost } \\
\text { follow-up in this }\end{array}$ & $\begin{array}{l}\text { cohort lost } \\
\text { follow-up in this }\end{array}$ \\
\hline study. & study. & study. & study. & study. \\
\hline
\end{tabular}

\section{References:}

1. Alfson DB, Ham SW. Type B Aortic Dissections: Current Guidelines for Treatment. Cardiology clinics. 2017;35(3):387-410.

2. Tadros RO, Tang GHL, Barnes HJ, Mousavi I, Kovacic JC, Faries P, et al. Optimal Treatment of Uncomplicated Type B Aortic Dissection: JACC Review Topic of the Week. Journal of the American College of Cardiology. 2019;74(11):1494-504.

3. Howard C, Sheridan J, Picca L, Reza S, Smith T, Ponnapalli A, et al. TEVAR for complicated and 
uncomplicated type B aortic dissection-Systematic review and meta-analysis. Journal of cardiac surgery. 2021;36(10):3820-30.

4. Jubouri M, Bashir M, Tan SZCP, Bailey D, Anderson R, Nienaber CA, et al. What is the optimal timing for thoracic endovascular aortic repair in uncomplicated Type B aortic dissection? Journal of cardiac surgery. 2021.

5. Yuan X, Clough RE, Nienaber CA. Management of Uncomplicated Type B Aortic Dissection. Hearts 2020, Vol 1, Pages 14-24. 2020;1(1):14-24.

6. Tjaden BL, Sandhu H, Miller C, Gable D, Trimarchi S, Weaver F, et al. Outcomes from the Gore Global Registry for Endovascular Aortic Treatment in patients undergoing thoracic endovascular aortic repair for type B dissection. Journal of vascular surgery. 2018;68(5):1314-23.

7. Torrent DJ, McFarland GE, Wang G, Malas M, Pearce BJ, Aucoin V, et al. Timing of thoracic endovascular aortic repair for uncomplicated acute type B aortic dissection and the association with complications. Journal of vascular surgery. 2021;73(3):826-35.

8. Xie E, Yang F, Liu Y, Xue L, Fan R, Xie N, et al. Timing and Outcome of Endovascular Repair for Uncomplicated Type B Aortic Dissection. European Journal of Vascular and Endovascular Surgery. 2021;61(5):788-97.

9. Xiang D, Wu F, Chen L, Liang H, Xiong B, Liang B, et al. Timing of endovascular repair impacts long-term outcomes of uncomplicated acute type B aortic dissection. Journal of vascular surgery. 2021.

10. Spinelli D, Weaver FA, Azizzadeh A, Magee GA, Piffaretti G, Benedetto F, et al. Endovascular treatment of complicated versus uncomplicated acute type B aortic dissection. The Journal of thoracic and cardiovascular surgery. 2021.

11. Bi Y, Yi M, Han X, Ren J. Clinical outcomes and quality of life in patients with acute and subacute type B aortic dissection after thoracic endovascular aortic repair. J Int Med Res. 2020;48(8).

12. Qin YL, Wang F, Li TX, Ding W, Deng G, Xie B, et al. Endovascular Repair Compared With Medical Management of Patients With Uncomplicated Type B Acute Aortic Dissection. Journal of the American College of Cardiology. 2016;67(24):2835-42.

13. Iannuzzi JC, Stapleton SM, Bababekov YJ, Chang D, Lancaster RT, Conrad MF, et al. Favorable impact of thoracic endovascular aortic repair on survival of patients with acute uncomplicated type B aortic dissection. Journal of Vascular Surgery. 2018;68(6):1649-55.

14. Xiang D, Kan X, Liang H, Xiong B, Liang B, Wang L, et al. Comparison of mid-term outcomes of endovascular repair and medical management in patients with acute uncomplicated type B aortic dissection. The Journal of thoracic and cardiovascular surgery. 2021;162(1):26-36.e1.

15. Nienaber CA, Rousseau H, Eggebrecht H, Kische S, Fattori R, Rehders TC, et al. Randomized comparison of strategies for type B aortic dissection: the INvestigation of STEnt Grafts in Aortic Dissection (INSTEAD) trial. Circulation. 2009;120(25):2519-28.

16. Nienaber CA, Kische S, Rousseau H, Eggebrecht H, Rehders TC, Kundt G, et al. Endovascular repair of type B aortic dissection: Long-term results of the randomized investigation of stent grafts in aortic dissection trial. Circulation: Cardiovascular Interventions. 2013;6(4):407-16.

17. Brunkwall J, Kasprzak P, Verhoeven E, Heijmen R, Taylor P, Alric P, et al. Endovascular repair of acute uncomplicated aortic type $\mathrm{B}$ dissection promotes aortic remodelling: 1 year results of the ADSORB trial. European journal of vascular and endovascular surgery : the official journal of the European Society for Vascular Surgery. 2014;48(3):285-91.

18. Enezate TH, Omran J, Al-Dadah AS, White C, Patel M, Mahmud E, et al. Thoracic endovascular repair versus medical management for acute uncomplicated type B aortic dissection. Catheterization 
and cardiovascular interventions : official journal of the Society for Cardiac Angiography \& Interventions. 2018;91(6):1138-43.

19. Hossack M, Patel S, Gambardella I, Neequaye S, Antoniou GA, Torella F. Endovascular vs. Medical Management for Uncomplicated Acute and Sub-acute Type B Aortic Dissection: A Meta-analysis. European journal of vascular and endovascular surgery : the official journal of the European Society for Vascular Surgery. 2020;59(5):794-807.

20. Nakamura K, Uchida T, Hamasaki A, Sadahiro M. How should we treat uncomplicated subacute type B aortic dissection in octogenarians? Journal of cardiothoracic surgery. 2019;14(1).

21. Gao HQ, Xu SD, Ren CW, Yang S, Liu CL, Zhen J, et al. Analysis of perioperative outcome and longterm survival rate of thoracic endovascular aortic repair in uncomplicated type B dissection: single-centre experience with 751 patients. European journal of cardio-thoracic surgery : official journal of the European Association for Cardio-thoracic Surgery. 2019;56(6):1090-6.

22. Li FR, Wu X, Yuan J, Wang J, Mao C, Wu X. Comparison of thoracic endovascular aortic repair, open surgery and best medical treatment for type B aortic dissection: A meta-analysis. International journal of cardiology. 2018;250:240-6.

23. Ameli-Renani S, Pavlidis V, Morgan RA. Secondary Endoleak Management Following TEVAR and EVAR. Cardiovascular and interventional radiology. 2020;43(12):1839-54.

24. Golzarian J, Valenti D. Endoleakage after endovascular treatment of abdominal aortic aneurysms: Diagnosis, significance and treatment. Eur Radiol. 2006;16(12):2849-57.

25. Bashir MR, Ferral H, Jacobs C, McCarthy W, Goldin M. Endoleaks after endovascular abdominal aortic aneurysm repair: management strategies according to CT findings. AJR American journal of roentgenology. $2009 ; 192(4)$.

26. Song C, Lu Q, Zhou J, Yu G, Feng X, Zhao Z, et al. The new indication of TEVAR for uncomplicated type B aortic dissection. Medicine. 2016;95(25).

27. Eggebrecht H, Thompson M, Rousseau H, Czerny M, Lönn L, Mehta RH, et al. Retrograde ascending aortic dissection during or after thoracic aortic stent graft placement insight from the european registry on endovascular aortic repair complications. Circulation. 2009;120(SUPPL. 1).

28. Xu SD, Huang FJ, Yang JF, Li ZZ, Yang S, Du JH, et al. Early and midterm results of thoracic endovascular aortic repair of chronic type B aortic dissection. The Journal of thoracic and cardiovascular surgery. 2010;139(6):1548-53.

29. Estrera AL, Shah P, Lee TY, Irani AD, Safi HJ. Repair of retrograde type a aortic dissection after thoracic endovascular aortic aneurysm repair using the modified elephant trunk technique. Vascular. 2009;17(2):11620 .

30. Wang L, Zhao Y, Zhang W, Shu X, Wang E, Guo D, et al. Retrograde Type A Aortic Dissection after Thoracic Endovascular Aortic Repair: Incidence, Time Trends and Risk Factors. Seminars in thoracic and cardiovascular surgery. 2021;33(3):639-53.

31. Ma T, Dong ZH, Fu WG, Guo DQ, Xu X, Chen B, et al. Incidence and risk factors for retrograde type A dissection and stent graft-induced new entry after thoracic endovascular aortic repair. Journal of vascular surgery. 2018;67(4):1026-33.e2.

32. Yammine H, Briggs CS, Stanley GA, Ballast JK, Anderson WE, Nussbaum T, et al. Retrograde type A dissection after thoracic endovascular aortic repair for type B aortic dissection. Journal of vascular surgery. 2019;69(1):24-33.

33. Nauta FJH, Tolenaar JL, Patel HJ, Appoo JJ, Tsai TT, Desai ND, et al. Impact of Retrograde Arch Extension in Acute Type B Aortic Dissection on Management and Outcomes. The Annals of thoracic surgery. 
2016;102(6):2036-43.

34. Chen Y, Zhang S, Liu L, Lu Q, Zhang T, Jing Z. Retrograde Type A Aortic Dissection After Thoracic Endovascular Aortic Repair: A Systematic Review and Meta-Analysis. Journal of the American Heart Association. 2017;6(9).

35. Weiss G, Wolner I, Folkmann S, Sodeck G, Schmidli J, Grabenwöger M, et al. The location of the primary entry tear in acute type B aortic dissection affects early outcome. European journal of cardio-thoracic surgery : official journal of the European Association for Cardio-thoracic Surgery. 2012;42(3):571-6.

36. Grabenwöger M, Alfonso F, Bachet J, Bonser R, Czerny M, Eggebrecht H, et al. Thoracic Endovascular Aortic Repair (TEVAR) for the treatment of aortic diseases: a position statement from the European Association for Cardio-Thoracic Surgery (EACTS) and the European Society of Cardiology (ESC), in collaboration with the European Association of Percutaneous Cardiovascular Interventions (EAPCI). European Journal of Cardio-Thoracic Surgery. 2012;42(1):17-24.

37. Dong Z, Fu W, Wang Y, Wang C, Yan Z, Guo D, et al. Stent graft-induced new entry after endovascular repair for Stanford type B aortic dissection. Journal of vascular surgery. 2010;52(6):1450-7.

38. Berkarda Z, Kondov S, Kreibich M, Czerny M, Beyersdorf F, Rylski B. Landing Zone Remodelling after Endovascular Repair of Dissected Descending Aorta. European journal of vascular and endovascular surgery : the official journal of the European Society for Vascular Surgery. 2020;59(6):939-45.

39. Jánosi RA, Tsagakis K, Bettin M, Kahlert P, Horacek M, Al-Rashid F, et al. Thoracic aortic aneurysm expansion due to late distal stent graft-induced new entry. Catheterization and cardiovascular interventions : official journal of the Society for Cardiac Angiography \& Interventions. 2015;85(2):E43-E53.

40. Zhao Y, Yin H, Chen Y, Wang M, Zheng L, Li Z, et al. Restrictive bare stent prevents distal stent graft-induced new entry in endovascular repair of type B aortic dissection. Journal of vascular surgery. 2018;67(1):93-103.

41. Huang CY, Hsu HL, Chen PL, Chen IM, Hsu CP, Shih CC. The Impact of Distal Stent Graft-Induced New Entry on Aortic Remodeling of Chronic Type B Dissection. The Annals of thoracic surgery. 2018;105(3):78593.

42. Jang H, Kim MD, Kim GM, Won JY, Ko YG, Choi D, et al. Risk factors for stent graft-induced new entry after thoracic endovascular aortic repair for Stanford type B aortic dissection. Journal of vascular surgery. 2017;65(3):676-85.

43. Li Q, Ma WG, Zheng J, Xu SD, Chen Y, Liu YM, et al. Distal Stent Graft-Induced New Entry After TEVAR of Type B Aortic Dissection: Experience in 15 Years. The Annals of thoracic surgery. 2019;107(3):718-24.

44. Kamman AV, Brunkwall J, Verhoeven EL, Heijmen RH, Trimarchi S, Kasprzak P, et al. Predictors of aortic growth in uncomplicated type B aortic dissection from the Acute Dissection Stent Grafting or Best Medical Treatment (ADSORB) database. Journal of vascular surgery. 2017;65(4):964-71.e3.

45. Spanos K, Nana P, Behrendt CA, Kouvelos G, Panuccio G, Heidemann F, et al. Management of Descending Thoracic Aortic Diseases: Similarities and Differences Among Cardiovascular Guidelines. Journal of endovascular therapy : an official journal of the International Society of Endovascular Specialists. 2021;28(2):323-31.

46. Fanelli F, Cannavale A, O'Sullivan GJ, Gazzetti M, Cirelli C, Lucatelli P, et al. Endovascular Repair of Acute and Chronic Aortic Type B Dissections: Main Factors Affecting Aortic Remodeling and Clinical Outcome. JACC Cardiovascular interventions. 2016;9(2):183-91.

47. Sigman MM, Palmer OP, Ham SW, Cunningham M, Weaver FA. Aortic morphologic findings after thoracic endovascular aortic repair for type B aortic dissection. JAMA Surg. 2014;149(9):977-83. 
48. Trimarchi S, Tolenaar JL, Jonker FH, Murray B, Tsai TT, Eagle KA, et al. Importance of false lumen thrombosis in type B aortic dissection prognosis. J Thorac Cardiovasc Surg. 2013;145(3 Suppl):S208-12.

49. Jonker FH, Trimarchi S, Rampoldi V, Patel VI, O'Gara P, Peterson M, et al. Aortic expansion after acute type B aortic dissection. The Annals of thoracic surgery. 2012;94(4):1223-9.

50. Tsai TT, Evangelista A, Nienaber CA, Myrmel T, Meinhardt G, Cooper JV, et al. Partial Thrombosis of the False Lumen in Patients with Acute Type B Aortic Dissection. New England Journal of Medicine. 2007;357(4):349-59.

51. Clough RE, Hussain T, Uribe S, Greil GF, Razavi R, Taylor PR, et al. A new method for quantification of false lumen thrombosis in aortic dissection using magnetic resonance imaging and a blood pool contrast agent. J Vasc Surg. 2011;54(5):1251-8.

52. Laquian L, Scali ST, Beaver TM, Kubilis P, Beck AW, Giles K, et al. Outcomes of Thoracic Endovascular Aortic Repair for Acute Type B Dissection in Patients With Intractable Pain or Refractory Hypertension. Journal of Endovascular Therapy. 2018;25(2):220-9.

53. Wang GJ, Cambria RP, Lombardi JV, Azizzadeh A, White RA, Abel DB, et al. Thirty-day outcomes from the Society for Vascular Surgery Vascular Quality Initiative thoracic endovascular aortic repair for type B dissection project. Journal of vascular surgery. 2019;69(3):680-91.

54. Heijmen R, Fattori R, Thompson M, Dai-Do D, Eggebrecht H, Degrieck I, et al. Mid-term outcomes and aortic remodelling after thoracic endovascular repair for acute, subacute, and chronic aortic dissection: the VIRTUE Registry. European journal of vascular and endovascular surgery : the official journal of the European Society for Vascular Surgery. 2014;48(4):363-71.

55. Patterson BO, Cobb RJ, Karthikesalingam A, Holt PJ, Hinchliffe RJ, Loftus IM, et al. A systematic review of aortic remodeling after endovascular repair of type B aortic dissection: methods and outcomes. The Annals of thoracic surgery. 2014;97(2):588-95.

56. Lee SJ, Kang WC, Ko YG, Woo Y, Ahn CM, Won JY, et al. Aortic Remodeling and Clinical Outcomes in Type B Aortic Dissection According to the Timing of Thoracic Endovascular Aortic Repair. Annals of vascular surgery. 2020;67:322-31.

57. Andacheh ID, Donayre C, Othman F, Walot I, Kopchok G, White R. Patient outcomes and thoracic aortic volume and morphologic changes following thoracic endovascular aortic repair in patients with complicated chronic type B aortic dissection. Journal of vascular surgery. 2012;56(3):644-50.

58. Omura A, Matsuda H, Fukuda T, Nomura Y, Kawasaki R, Murakami H, et al. Midterm outcomes of thoracic endovascular repair for uncomplicated type B aortic dissection with double-barrel type. Gen Thorac Cardiovasc Surg. 2019;67(12):1021-9.

59. Kitamura T, Torii S, Oka N, Horai T, Nakashima K, Itatani K, et al. Key success factors for thoracic endovascular aortic repair for non-acute Stanford type B aortic dissection+. European Journal of CardioThoracic Surgery. 2014;46(3):432-7.

60. Mizoguchi T, Zempo N, Kaneda Y. Early and Mid-Term Outcomes Following TEVAR for Chronic Type B Aortic Dissection. Annals of vascular diseases. 2017;10(4):345-50.

61. Bedi VS, Swain P, Yadav A. Medical therapy versus TEVAR for uncomplicated type B aortic dissection. Indian journal of thoracic and cardiovascular surgery. 2019;35(Suppl 2):174-8.

\section{Hosted file}

Tables.docx available at https://authorea.com/users/445492/articles/553895-mid-andlong-term-outcomes-of-thoracic-endovascular-aortic-repair-in-acute-and-subacuteuncomplicated-type-b-aortic-dissection 